\title{
Inequalities and convergence of health outcomes in South Asian countries
}

\author{
Sumit Kumar
}

Assistant Professor, Department of Economics, Sri Guru Granth Sahib World University, Fathehgarh Sahib, India.

\begin{abstract}
For human development of South Asian countries, which houses more than one-fifth of world's population, it becomes crucial to study health inequalities between and within these countries. The aim of this paper is to explore the extent of health inequalities and convergence of health outcomes as represented by life expectancy and infant mortality rates among the South Asian countries. The statistical methods Gini coefficient, $\sigma$, and $\beta$-convergence analysis are utilized to study inequalities and convergence-divergence, which are well established in macroeconomic growth analyses. For the study longitudinal data over the period 1996-2012 for Infant Mortality rate (IMR) and Life expectancy (LE) is utilized. The results of the analysis indicate that there have been large inequalities in IMR and these are still increasing among the countries. However, in case of LE the inequalities are small and are on decline over the period of time. Further, the tests for convergence reveal that the IMR and LE have not been converged in the period 1996-2012 and no convergence clubs has been formed. The present analyses highlights that the relative positions of countries among the South Asia have changed little and the trend of large inequalities among the countries continues. Further research to identify economic and social policy measures which decline the large inequalities among the countries can be rewarding exposition for all the stakeholders.
\end{abstract}

Keywords: Inequality, Infant mortality, Life expectancy, Convergence, South Asia.

\section{Introduction}

Today's knowledge economies rely on human capital for economic growth and literature on economic growth also recognizes that human capital is a principal factor for growth in economies. ${ }^{1-3}$ The basic quality of human capital constitutes the education of population and health status of population. Health status of the population affects the household productivity and local economy, and thus in turn national and international development. ${ }^{4-5}$ The commission on macroeconomics and health also recognizes that countries with poor conditions of health and education have tough time achieving a sustained economic growth than countries with better conditions of health and education. ${ }^{6}$ There are empirical evidences which show a positive association between health and economic growth. ${ }^{7-11}$

Large number of empirical studies confirming the importance of health withstanding, there has also been studies confirming large inequalities in health among and within the countries. ${ }^{12-14}$ The empirical literature also establish that on average socially and economically backward groups suffer from worse health than their better off counterparts due to malnutrition, lack of food, unclean water, low levels of sanitation and housing, failure to deal with the environments that lead to high exposure to infectious agents, and lack of accessibility and affordability of medical care. ${ }^{6}$ Reducing these health inequalities is crucial for variety of critical reasons. Firstly, these are central for equity and justice. It conditions the capabilities of individuals and groups to

\section{Practice Points}

- There exist large inequalities and disparities among the South Asian countries in the health status.

- Over the years the inequalities in IMR have increased. Gini coefficient of IMR in 1996 increased from 0.163 to 0.25 in 2012 .

- In case of LE, Gini coefficient in 1996 declined from 0.035 to 0.020 in 2012. The inequalities are small and have declined.

- The relative positions of countries among the South Asia have changed little and the trend of inequalities among the countries continues especially on IMR.

- The tests for convergence reveal that the IMR and LE have not been converged in the period 1996-2012.

participate in and benefit from social and economic development. Secondly, better health enables population to participate in society with potentially positive consequences for economic performance. Thirdly, health inequalities most adversely impact the vulnerable and impoverished populations, thereby, further reducing their capacity and capability. ${ }^{12}$ South Asia, which houses more than one-fifth of the world's

Correspondence: Dr. Sumit Kumar, Assistant Professor, Department of Economics, Sri Guru Granth Sahib World University, Fathehgarh Sahib, India. Email: sumitkumar2382@gmail.com. 
population, is also not an exception to the phenomenon of health inequalities. ${ }^{13}$ On the one hand where infant mortality is high in Afghanistan (117 per 1000 live births in 2014), however, on the other hand, it is low in Sri Lanka (9 per 1000 live births in 2014). ${ }^{15}$ The differences in health outcomes among the South Asian countries withstanding, there are also widespread health inequalities among the countries also. Children belonging to the poorest stratum are more likely to be stunted or malnourished in almost every country of South Asia, although the gap is relatively less glaring in Maldives and Sri Lanka. ${ }^{13}$ The empirical analysis using the data from 1990-2006 of the South Asian countries also supported the fact that there are health inequalities and these are also not converging very fast over time. The lagging regions are unable to promptly catch up with the leading regions of South Asia on health outcomes. ${ }^{15}$ Apart from understanding the causes, consequences and remedies of widespread disparities in health, there is also need to systematically study the extent of health inequalities and also examining whether the lagging regions are catching up with leading regions from time to time. The present paper aims at to explore the health inequalities and convergence of health outcomes over time in South Asian countries.

\section{Materials and methods}

To understand the inequalities and more specifically convergence, it is necessary to utilize longitudinal or time-series data. ${ }^{16}$ Therefore; the present paper uses the longitudinal data from World Bank database from 1996 to 2012 of South Asian countries. ${ }^{15}$ The study explores the health inequalities in the health outcomes among Bangladesh, Bhutan, India, Sri Lanka, Nepal, and Pakistan. The data on few indicators for the period 1996 -2012 was not available for Afghanistan, Myanmar, and Maldives and therefore, are not included in the present analysis. Life expectancy at birth (LE) and infant mortality rate (IMR) (per 1000 live births) are utilized as indicators for healthcare outcomes. To explore the extent of inequalities among the health outcomes, coefficient of variation and Gini co-efficient are utilized. ${ }^{12}$ Furthermore, to study convergence of health outcomes following well-accepted models has also been utilized: ${ }^{17-18}$

\section{(a) Absolute $\sigma$-convergence}

(b) Absolute/Unconditional $\beta$-convergence.

(c) Conditional $\beta$-convergence

(a) Absolute $\sigma$-Convergence:

The standard deviation (S.D) or Coefficient of Variation of life expectancy at birth and infant mortality rate is analyzed for $\sigma$-convergence. There is sigmaconvergence if the standard deviation tends to decline over time. It is estimated using the following equation:

$$
\sigma_{\mathrm{t}} \text { or } \mathrm{CV}_{\mathrm{t}}=\alpha_{0}+\alpha_{1} * \mathrm{t}+\mu_{\mathrm{t}}
$$

Where $\sigma_{t}$ and $C V_{t}$ represent standard deviation and coefficient of variation. The negative value of slope coefficient $\alpha_{1}$ would indicate presence of $\sigma$ convergence. In the present analysis, coefficient of variation is utilized as dependent variable. (b) Absolute $\beta$-convergence:

The $\beta$-convergence is a primary focus of the researchers because it serves as a necessary condition for ' $\sigma$ convergence'. The existence $\beta$-convergence can be examined empirically by estimating cross-sectional regression of life expectancy at birth and infant mortality rate on the initial level of it. The following regression frame work is used to examine $\beta$ convergence.

$$
\mathrm{DY}=\alpha_{0}+\alpha_{1} \mathrm{Yo}+\mathrm{m}
$$

Where DY is the change in values $\left(\log _{n}\left(Y_{t}-Y_{o}\right)\right), Y_{o}$ is the value in the base year $\left(\log _{n} Y o\right)$ and $m$ is the error term that is assumed to satisfy the Gauss Markov assumptions. If the regression coefficient $\alpha_{1}<0$ and statistically significant then this signifies convergence.

\section{(c) Conditional $\beta$-convergence:}

The unconditional or absolute $\beta$-convergence hypothesis is tested when countries have the same initial conditions. For testing conditional $\beta$-convergence, an additional explanatory variable/control variable $\mathrm{D}$ is introduced.

$$
\begin{array}{r}
D Y_{i t}=\alpha_{0}+\alpha_{1} Y_{i t-1}+\alpha_{2} D_{i t}+m_{i t} \\
i=1,2, . .6, t=1,2, \ldots 17
\end{array}
$$

Where, $D Y_{i t}$ is the change in value $\left(\log _{n}\left(Y_{t}-Y_{t-1}\right)\right), Y_{i t-1}$ is the value in the base year $\left(\operatorname{Iog}_{n} Y_{t-1}\right)$. The $D_{i t}$ is Gross domestic product of countries over the period of 1995 to 2012 (in US \$). The fixed effect and random effect panel data estimation techniques are used to estimate the coefficients. To select the appropriate model among the fixed effect and random effect models, Hausman test is utilized. ${ }^{19}$ The positive or negative sign of the estimated ' $\alpha_{1}$ ' and ' $\alpha_{2}$ ' coefficient establish the divergence or convergence respectively.

\section{Results}

Infant mortality rate (per 1000 live births) and Life expectancy at birth (in years) of South Asian countries are studied from 1995 to 2012 and are presented in Figure 1 and Figure 2. IMR of South Asian countries has declined over the period of time. Pakistan had the highest IMR and IMR of Sri Lanka was lowest in 1995 and the same trend continued at the end of 2012.

However, LE of Sri Lanka was highest and of Bhutan was lowest in 1995; however, Sri Lanka had the highest life expectancy at the end of 2012 whereas Bhutan outperformed few of its neighboring countries and Life expectancy of Pakistan and India was lowest among the compared group of countries in 2012. From the graphical analysis, it is clear that there are inequalities between these countries on account of LE and IMR. On the one hand, the inequalities in IMR have been high among the countries and it has been increasing from 1995 to 2012 (Figure 3). On the other hand, inequalities in LE have been low and it has declined in the period of 1995-2012 (Figure 4).

As mentioned and discussed in the methodology, to measure converge of LE and IMR among the South Asian Countries, absolute $\sigma$-convergence, absolute 


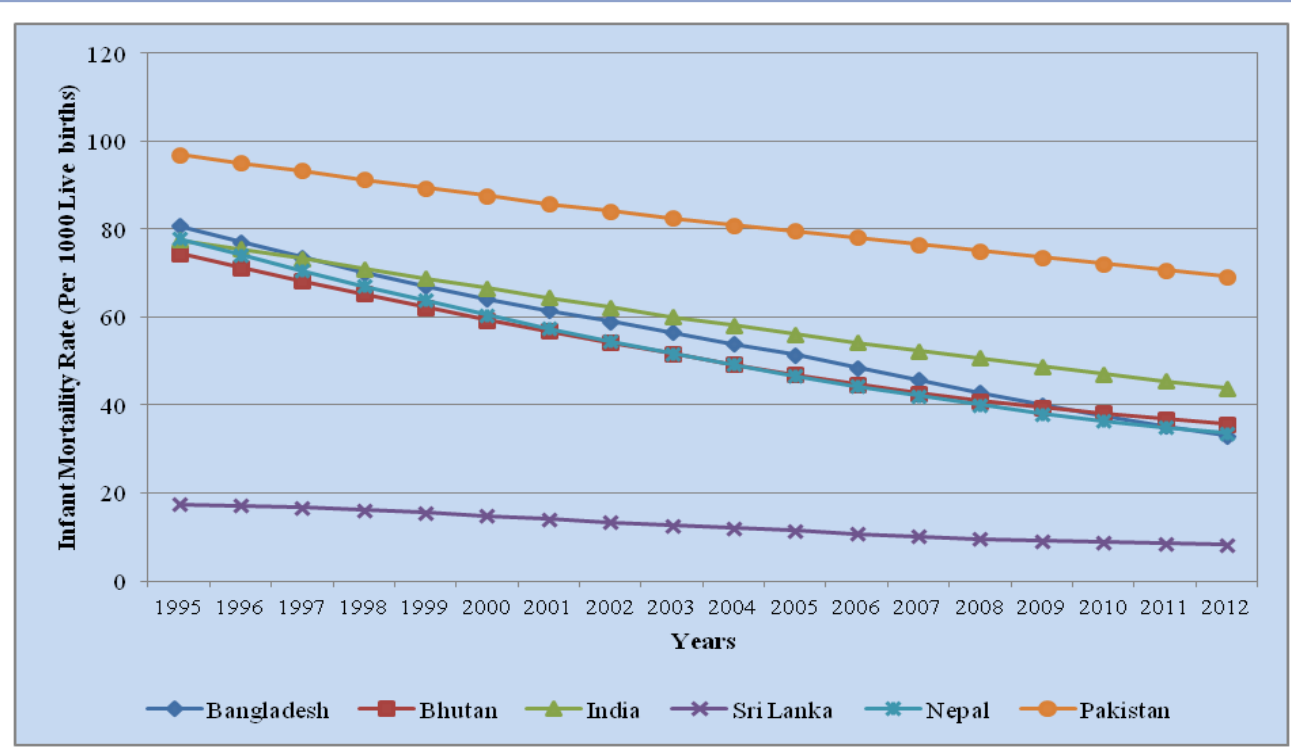

Figure 1: Infant mortality rate (per 1000 live births) in South Asian countries in 1995-2012 15

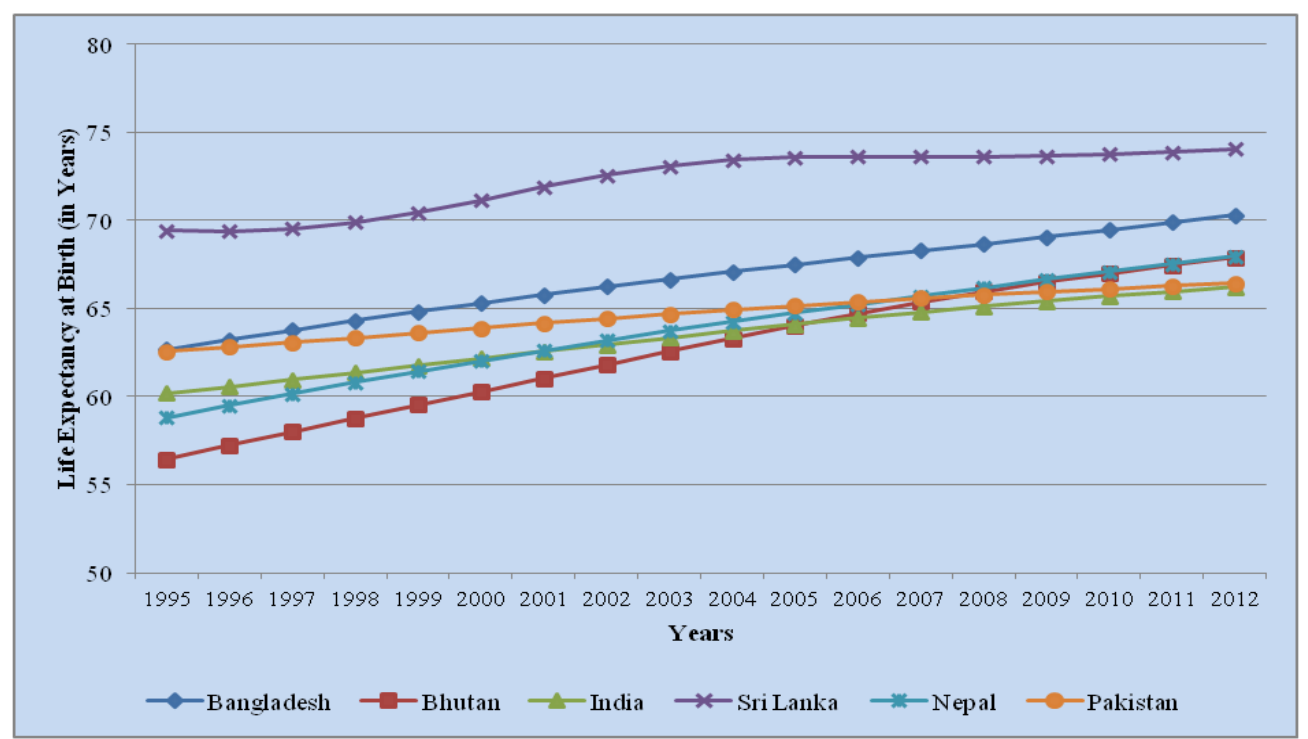

Figure 2: Life Expectancy at birth (in years) in South Asian countries in 1995-2012 ${ }^{15}$

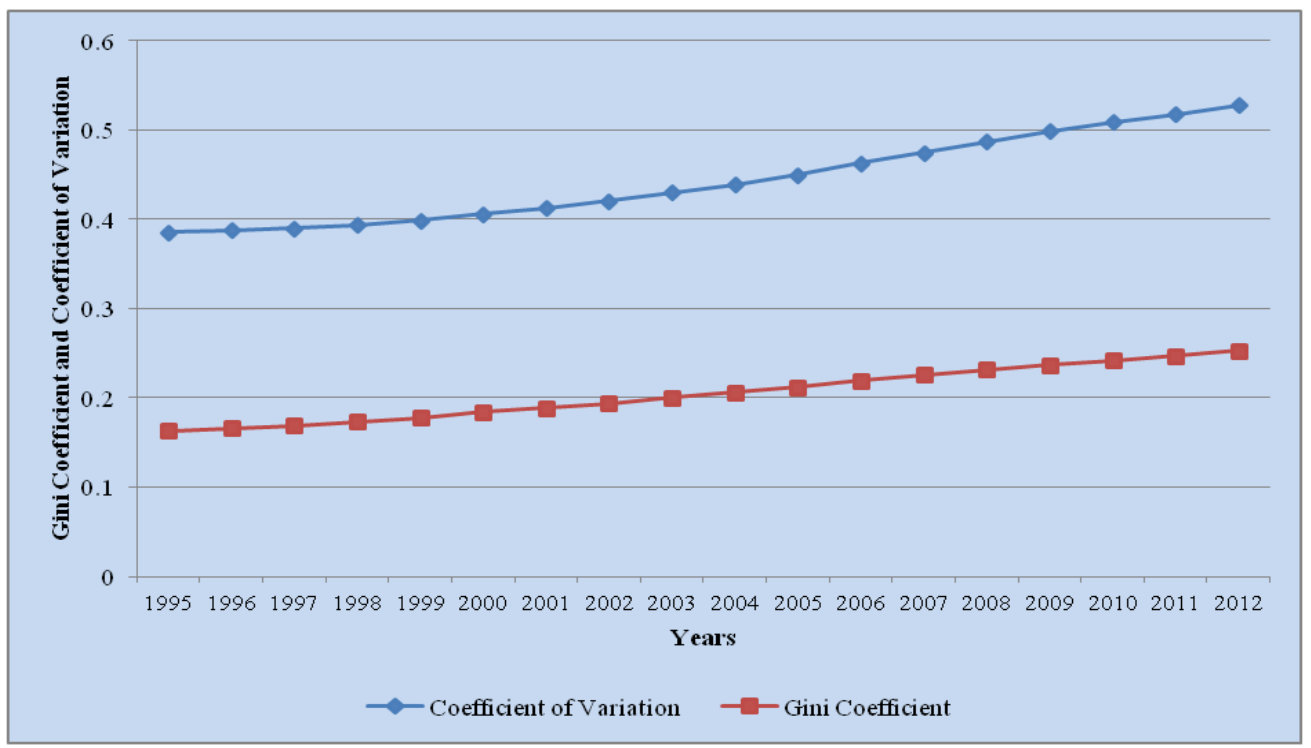

Figure 3: Inequality in infant mortality rate (per 1000 live births) in South Asian countries in $1995-2012$ 


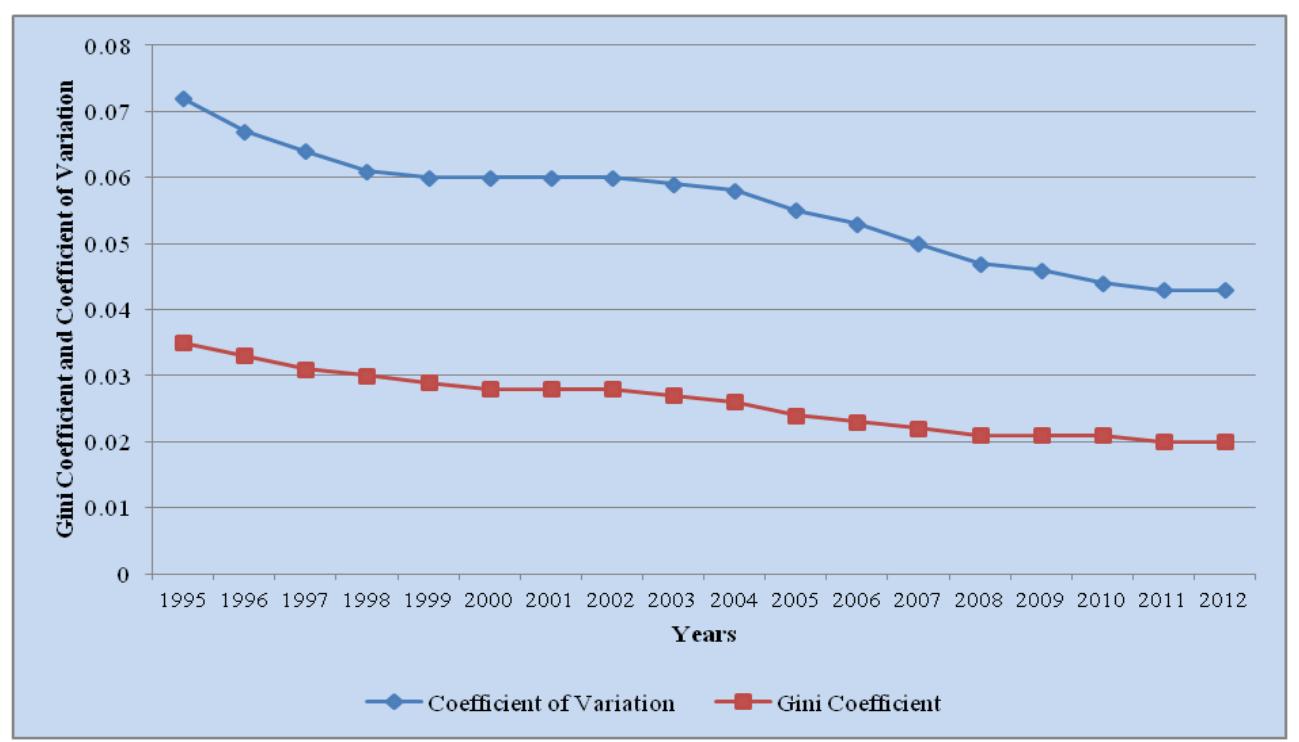

Figure 4: Inequality in life expectancy at birth (in years) in South Asian countries, 1995-2012 ${ }^{15}$

$\beta$-convergence, conditional $\beta$-convergence has been explored and is presented as follows:

\section{Absolute $\sigma$-Convergence}

The coefficient of variation among countries' LE and IMR in years from 1995 to 2012 are utilized as dependent variable and time period is utilized as independent variable (Table 1). The positive and statistically significant sign of slope variables for IMR suggest that there is absolute $\sigma$-divergence among the South Asian countries over the years. However, on the other hand for LE the trend is opposite and negative and statistically significant sign of slope variables suggest that there is absolute $\sigma$-convergence among the South Asian countries over the years.

\section{Absolute $\beta$-Convergence}

The unconditional $\beta$-Convergence analysis is done among countries' LE and IMR in years from 1995 to 2012 for pooled and panel data separately. The Hausman test is also utilized to choose among the fixed effect or random effect panel data models. The test statistic for Hausman test for both IMR and LE suggest that the null hypothesis cannot be rejected and it can be concluded that there is no substantial and significant difference between fixed effect and random effect estimators. The estimates of pooled and panel data significantly establish that there has been no convergence or divergence in IMR or LE over the years among the countries as the coefficient is very approximately zero (Table 2 and 3 ).

Table 1: Absolute $\sigma$-convergence of infant mortality rates and life expectancy

\begin{tabular}{|c|c|c|}
\hline & Infant mortality rates & Life expectancy \\
\hline $\mathrm{t}$ (slope) & $0.766^{*}$ & $-0.111^{*}$ \\
\hline Constant & $33.15^{*}$ & $6.43^{*}$ \\
\hline $\mathrm{N}$ & 18 & 18 \\
\hline $\mathrm{R}^{2}$ & 0.96 & 0.91 \\
\hline
\end{tabular}

Note: $* * *, * * *$ signify significant at $1 \%, 5 \%, 10 \%{ }^{15}$

\section{Conditional $\beta$-Convergence}

The conditional $\beta$-convergence analysis is presented in Table 4 and 5 . Within this method of analysis two forms of convergence are distinguished: conditional and absolute. Conditional convergence occurs if the estimated coefficient(s) of the auxiliary variables (in the present study GDP of the respective country in billion \$) are statistically significant, indicating that there are differences across countries which direct each one to converge to its own steady state, allowing the possibility of 'convergence clubs' to be formed. Convergence clubs occur when sub-groups of countries in a sample converge to a similar level, which is different from the levels attained by other sub-groups in the sample.

Alternatively, absolute convergence indicates that all countries in the sample converge to the same steady state. The test statistic for Hausman test for both IMR and LE suggest that the null hypothesis cannot be rejected and it can be concluded that there is no substantial and significant difference between fixed effect and random effect estimators of conditional convergence analysis. The conditional estimates also reveal that there has been no convergence or divergence in IMR or LE over the years among the countries.

\section{Discussion}

The results provide evidence that on account of health outcomes lagging regions of South Asia are also improving. The life expectancy at birth has increased in the South Asian countries and Infant mortality has declined. This finding gives us hope that the South Asian countries are progressing on health indicators. On the negative side, there is little evidence of convergence in health outcomes. There are no greater proportionate reductions in infant mortality in initially laggard countries. Therefore, these countries are not catching up with better performing countries fast enough, and more needs to be done to accelerate health improvements in the lagging countries. Furthermore, the health outcomes of South Asia are also puzzling. ${ }^{20-22}$ 
Table 2: Absolute/Unconditional $\beta$-convergence of Infant Mortality rates ${ }^{15}$

\begin{tabular}{|c|c|c|c|}
\hline & \multirow[b]{2}{*}{ Pooled } & \multicolumn{2}{|c|}{ Panel } \\
\hline & & $\begin{array}{l}\text { Fixed } \\
\text { Effect }\end{array}$ & $\begin{array}{c}\text { Random } \\
\text { Effect }\end{array}$ \\
\hline Base & $0.0001 *$ & $0.0000 * * *$ & $0.0001 * *$ \\
\hline Constant & $-0.0235^{*}$ & $-0.0200 *$ & $-0.0204^{*}$ \\
\hline $\mathrm{N}$ & 102 & 102 & 102 \\
\hline $\mathrm{R}^{2}$ & 0.21 & 0.21 & 0.21 \\
\hline \multicolumn{2}{|c|}{$\begin{array}{c}\text { Hausman Test } \\
\mathrm{H}_{0}: \text { Fixed effect and } \\
\text { Random effect } \\
\text { estimators do not differ } \\
\text { substantially. }\end{array}$} & \multicolumn{2}{|c|}{$\begin{array}{c}0.65 \\
(0.419) \\
\text { Result: Do not reject the } \\
\text { null }\end{array}$} \\
\hline
\end{tabular}

Note: $*, * *, * * *$ signify significant at $1 \%, 5 \%, 10 \%{ }^{15}$

Table 4: Conditional $\beta$-convergence of infant mortality rates $^{15}$

\begin{tabular}{|c|c|c|c|}
\hline \multirow{2}{*}{} & \multirow{2}{*}{ Pooled } & \multicolumn{2}{|c|}{ Panel } \\
\cline { 3 - 4 } & $\begin{array}{c}\text { Fixed } \\
\text { Effect }\end{array}$ & $\begin{array}{c}\text { Random } \\
\text { Effect }\end{array}$ \\
\hline Base & $0.0001^{*}$ & 0.0000 & $0.0000^{* * *}$ \\
\hline $\begin{array}{c}\text { GDP (In } \\
\text { Billion \$) }\end{array}$ & $0.0000^{* *}$ & 0.0000 & 0.0000 \\
\hline Constant & $-0.0238^{*}$ & $-0.0195^{*}$ & $-0.0201^{*}$ \\
\hline $\mathrm{N}$ & 102 & 102 & 102 \\
\hline $\mathrm{R}^{2}$ & 0.25 & 0.127 & 0.188 \\
\hline $\begin{array}{c}\text { Hausman Test } \\
\mathrm{H}_{0}: \text { Fixed effect and } \\
\text { Random effect } \\
\text { estimators do not differ } \\
\text { substantially. }\end{array}$ & \multicolumn{2}{|c|}{0.97} \\
$(0.616)$ \\
\hline
\end{tabular}

Note: $* * *, * * *$ signify significant at $1 \%, 5 \%, 10 \%{ }^{15}$

Income growth should stimulate development as people demand more and better health with increase in income.

${ }^{23}$ However, in South Asia, despite rapid increase in income the health outcomes has not been improved simultaneously. On the one hand, India has higher gross national income but infant mortality rates are dismally high, whereas on the other hand, Sri Lanka has not witnessed income growth like India but perform better than India on health outcomes. ${ }^{24}$ For better health outcomes especially in lagging countries and also to reduce poverty prevalent in South Asian countries, the focus should not be alone on income-generation, infrastructure, and market integration, but also on greater investments in social sector as well as capacity building to enable better use of such investments. ${ }^{23}$ Moreover, there is also need for continuous knowledge exchange and sharing between countries as each country can learn strategies from success stories of another country to tackle issues related to health outcomes. ${ }^{12}$

\section{Conclusion}

In the present study convergence of health care outcomes in South Asian countries were studied. For testing $\sigma-, \beta$-, and conditional $\beta$-convergence panel data over the period 1996-2012 for infant mortality rate and life expectancy was utilized. The results of the analysis indicate that there has been $\sigma$-convergence in LE and $\sigma$-divergence in IMR among the selected South Asian
Table 3: Absolute/Unconditional $\beta$-convergence of life expectancy $^{15}$

\begin{tabular}{|c|c|c|c|}
\hline & \multirow[b]{2}{*}{ Pooled } & \multicolumn{2}{|c|}{ Panel } \\
\hline & & $\begin{array}{l}\text { Fixed } \\
\text { Effect }\end{array}$ & $\begin{array}{c}\text { Random } \\
\text { Effect }\end{array}$ \\
\hline Base & $-0.0002 *$ & $-0.0003 *$ & $-0.0003 *$ \\
\hline Constant & $0.0175^{*}$ & $0.0202 *$ & $0.0200 *$ \\
\hline $\mathrm{N}$ & 102 & 102 & 102 \\
\hline $\mathrm{R}^{2}$ & 0.40 & 0.40 & 0.40 \\
\hline \multicolumn{2}{|c|}{$\begin{array}{c}\text { Hausman Test } \\
\mathrm{H}_{0}: \text { Fixed effect and } \\
\text { Random effect } \\
\text { estimators do not differ } \\
\text { substantially. }\end{array}$} & \multicolumn{2}{|c|}{$\begin{array}{c}0.16 \\
(0.688) \\
\text { Result: Do not reject the null }\end{array}$} \\
\hline
\end{tabular}

Note: $* * *, * * *$ signify significant at $1 \%, 5 \%, 10 \%{ }^{15}$

Table 5: Conditional $\beta$-convergence of life expectancy ${ }^{15}$

\begin{tabular}{|c|c|c|c|}
\hline & \multirow[b]{2}{*}{ Pooled } & \multicolumn{2}{|c|}{ Panel } \\
\hline & & $\begin{array}{l}\text { Fixed } \\
\text { Effect }\end{array}$ & $\begin{array}{c}\text { Random } \\
\text { Effect }\end{array}$ \\
\hline Base & $-0.0002 *$ & $-0.0003^{*}$ & $-0.0003 *$ \\
\hline $\begin{array}{c}\text { GDP (In } \\
\text { Billion \$) }\end{array}$ & $0.0000 *$ & 0.0000 & 0.0000 \\
\hline Constant & $0.0186^{*}$ & $0.0203^{*}$ & $0.0199 *$ \\
\hline $\mathrm{N}$ & 102 & 102 & 102 \\
\hline $\mathrm{R}^{2}$ & 0.49 & 0.388 & 0.409 \\
\hline \multicolumn{2}{|c|}{$\begin{array}{c}\text { Hausman Test } \\
\mathrm{H}_{0}: \text { Fixed effect and } \\
\text { Random effect } \\
\text { estimators do not differ } \\
\text { substantially. }\end{array}$} & Result: Do & $\begin{array}{l}\text { ject the null } \\
\text { jell }\end{array}$ \\
\hline
\end{tabular}

countries. The test for $\beta$-convergence confirmed that the IMR and LE have not been converged in the period 1996-2012. Further, test for conditional $\beta$-convergence also confirmed that the IMR and LE have not been converged in the period 1996-2012 and no convergence clubs has been formed.

From a societal perspective the measurement of convergence in social welfare provision such as health care reveal that things are becoming more similar over time, which implies a greater degree of equality and integration is being achieved within the countries of the South Asia. However, the present analyses indicate that the relative positions of countries among the South Asia have changed little and the trend of large inequalities among the countries continues. Further research to identify economic and social policy measures which decline the large inequalities among the countries can be fruitful.

\section{References}

1. Becker GS. Human capital: A theoretical and empirical analysis, with special reference to education. New York: National Bureau of Economic Research, 1964.

2. Sala-i-Martin X, Doppelhofer G, Miller RI. Determinants of long-run growth: a Bayesian 
averaging of classical estimates (BACE) approach. Am Econ Rev 2004; 94(4): 813-35.

3. Benhabib J, Spiegel MM. The role of human capital in economic development: evidence from aggregate cross-country data. $J$ Monetary Econ 1994; 34(2):143-73.

4. Bloom DE, Canning D. The health and wealth of nations. Science 2000; 287: 1207-9.

5. Bloom DE, Canning D. Population health and economic growth. Washington DC: World Bank, 2008.

6. WHO. Macroeconomics and health: Investing in health for economic development. Report of the Commission on Macroeconomics and Health. Geneva: World Health Organization, 2001.

7. Kalemli-Ozcan S, Ryder HE, Weil DN Mortality decline, human capital investment, and economic growth. J Dev Econ 2000; 62(1):1-23.

8. Bloom DD, Canning D, Graham B. Longevity and life cycle savings. Scand J Econ 2003; 105:319-38.

9. Jamison D, Lau L, Wang J. Health's contribution to economic growth in an environment of partially endogenous technical progress. Maryland: National Institutes of Health, 2004.

10. Bhargava A, Jamison D, Lau LJ, Murray, CJL. Modeling the effects of health on economic growth. J Health Econ 2001; 20: 423-40.

11. Alsan M, Bloom DE, Canning D. The effect of population health on foreign direct investment inflows to low- and middle-income countries. World Dev 2006; 34(4): 613-30.

12. WHO. Health inequities in the South-East Asia region: Magnitude and trends and what contributes to health inequities. Geneva: World Health Organization, 2007.

13. Martín R, Béteille T, Li Y, Mitra PK, Newman JL. Addressing inequality in South Asia. Washington DC: World Bank, 2015.
14. Ghani E, Iyer L, Mishra S. Are lagging regions catching up with leading regions? In: Ghani $\mathrm{E}$ (ed). The poor half billion in South Asia. What is holding back lagging regions? New Delhi: Oxford University Press, 2010.

15. World Bank. Data Bank, 2015. http:// databank.worldbank.org/data/home.aspx (accessed 31 Dec 2015)

16. Leonardi R. Convergence, cohesion and integration in the European Union. Basingstoke: Macmillan, 1995.

17. Nixon J. Convergence analysis of health care expenditure in the EU countries using two approaches. Heslington: University of York, 1999.

18. Kerem K, Puss T, Viies M, Maldre R. Health and convergence of health care expenditure in EU. Int Bus Econ J 2008; 7(3): 29-44

19. Greene WH. Econometric analysis. New Delhi: Pearson Education, 2003.

20. Deaton A. Height, health, and development. PNAS Col 2007;104(33):13232-7

21. Das J, Hammer J, Devarajan S, Prichett, L. Will a Wealthier India be a Healthier India? New Delhi: Presented at NBER/NCAER Conference on Growth in India, 2006.

22. Duflo A. Health shocks and economic vulnerability in rural India: Break the vicious circle. Sri City: Center for Micro Finance, IFMR, 2006.

23. Ghani E. Development disparities and peculiarities. In Ghani E, ed. by. The poor half billion in South Asia. What is holding back lagging regions? New Delhi: Oxford University Press, 2010.

24. Ministry of Health and Family Welfare (MoHFW). Report of national commission on macroeconomics and health. New Delhi MoHFW, 2005. 